\title{
PELATIHAN PEMBELAJARAN BERBASIS EDMODO DI MTS DARUL HIKMAH NGOMPAK NGRAMBE NGAWI
}

\author{
Oki Ribut Yuda Pradana, Heri Cahyono, Arum Dwi Rahmawati, \\ Anwas Mashuri, Budi Sasomo \\ STKIP Modern Ngawi \\ (Okirbt@gmail.com,085746064501)
}

\begin{abstract}
ABSTRAK
Guru mendapatkan peran penting dalam kemajuan sumber daya manusia. Sebagai pendidik guru harus memiliki inovasi untuk membuat pembelajaran menjadi efektif. Berdasarkan hal tersebut, perlu dibuat suatu pembelajaran yang inovatif dari praktisi pendidikan salah satunya pembelajaran berbasis Edmodo.Pengabdian ini bertujuan untuk membantu guru dalam menerapkan model pembelajaran inovatif di SMP/MTs dan meningkatkan minat belajar siswa.Pengabdian ini menggunakan power point dan situs Edmodo dalam pelaksanaannya. Materi disampaikan menggunakan metode ceramah, tanya jawab, simulasi, dan evaluasi. Setelah pelatihan, guru memberikan kesan positif kepada pelatihan ini. Mereka menjadi terbiasa menggunakan situs ini dan langsung menerapkan kepada siswanya.

Kesimpulan dari pengabdian ini adalah pelatihan-pelatihan yang mengacu kepada kreativitas guru sangat perlu dilakukan. Apabila guru bisa berinovasi maka proses pembelajaran akan terasa menyenangkan dan lebih menarik. Seharusnya, pemerintah lebih tanggap dalam masalah perkembangan pendidikan di Indonesia.
\end{abstract}

\section{Kata kunci : Edmodo, Pembelajaran, Pembeajaran Inovatif}

\begin{abstract}
Teachers get an important role in the progress of human resources. As educators teachers must have innovations to make learning effective. Based on this, it needs an innovative learning from education practitioners one of which is Edmodobased learning. This service aims to assist teachers in applying innovative learning models in Junior High School/ Madrasah Tsanawiyah and increase student interest in learning. This service uses Power Point and Edmodo website in its implementation. The material was delivered using lecture, question and answer, simulation, and evaluation methods. After the training, the teacher gives a positive impression on this training. They become accustomed to using this site and directly applying to their students.

The conclusion of this dedication is training that refers to teacher creativity is very necessary. If the teacher can innovate, the learning process will be fun and more interesting. Supposedly, the government is more responsive in matters of educational development in Indonesia.
\end{abstract}

Keywords : Edmodo, Learning, Innovative Learning 


\section{PENDAHULUAN}

Berawal dari pandangan umum bahwa di era globalisasi saat ini kualitas sumber daya manusia harus ditingkatkan, kami merumuskan bahwa hal mendasar yang patut dikembangkan adalah kreativitas dan intelektual manusia. Hal ini tidak terlepas dari bagaimana cara kita menjawab tantangan pembangunan nasional, terutama di bidang ilmu pengetahuan dan teknologi.

Pelajar adalah bagian utama dari masyarakat ilmiah yang mampu bergerak dinamis seiring perkembangan zaman. Beragam aktivitas telah dilakukan oleh para pelajar dalam mengukuhkan perannya sebagai komponen pembangunan. Aksi-aksi produktif, inovatif, dan kreatif yang diwujudkan oleh pelajar tidak pernah meninggalkan nuansa ilmiah yang menjadi ciri khasnya.

Guru mendapatkan peran penting dalam kemajuan sumber daya manusia. Sebagai pendidik guru harus memiliki inovasi untuk membuat pembelajaran menjadi efektif. Pembelajaran yang membosankan dapat menurunkan minat belajar siswa. Berdasarkan hal tersebut, perlu dibuat suatu pembelajaran yang inovatif dari praktisi pendidikan salah satunya pembelajaran berbasis Edmodo.

Kustandi mengemukakan bahwa media difungsikan sebagai sarana untuk mencapaitujuan pembelajaran (Kustandi, 2011). Edmodo adalah platform microblogging pribadi yang dikembangkan untuk guru dan siswa, dengan mengutamakan privasi siswa.
Yunus mengatakan Edmodo merupakan salah satu pembelajaraan yang kolaboratif (Yunus, 2013). Sejalan dengan hal terebut, Putri Fitriasari menyimpulkan bahwa edmodo sangat mudah digunakan oleh guru, melalui edmodo guru juga bisa melakukan diskusi seperti di kelas nyata (Putri, 2017).

Pengabdian ini bertujuan untuk membantu guru dalam menerapkan model pembelajaran inovatif di SMP/MTs dan meningkatkan minat belajar siswa.

\section{BAHAN DAN METODE}

Pengabdian kepada masyarakat ini berupa pelatihan kepada guru MTs Darul Hikmah di desa Ngompak, Kecamatan Ngrambe, Kabupaten Ngawi, Jawa Timur. Pengabdian kepada masyarakat ini menggunakan Power Point yang berisi materi tentang Edmodo dan website Edmodo yaitu www.edmodo.com.

\section{HASIL}

Pada saat pelaksanaan pelatihan banyak guru yang belum bisa menerapkan pembelajaran berbasis Edmodo. Semua guru masih menggunakan pembelajaran tatap muka di sekolah. Saat pelatihan berlangsung, guru sangat antusias mendengarkan materi yang disampaikan. Mungkin pembelajaran ini baru pertama kali mereka ketahui.

Saat Simulasi, guru sudah terbiasa menggunakan Edmodo. Pada sesi evaluasi, kami meminta komentar dari beberapa guru tentang tanggapan siswa saat pembelajaran 
berlangsung. Menurut pengamatan mereka, kreativitas guru sangat perlu sering dilakukan. banyak siswa antusias pada pembelajaran ini. Apabila guru bisa berinovasi maka proses

\section{PEMBAHASAN}

Edmodo membuat guru lebih kreatif dalam menerapkan proses pembelajaran. Banyak faktor yang menyebabkan mereka kurang kreatif seperti waktu dirumah yang sangat kurang untuk merancang pembelajaran karena mengurus urusan rumah tangga, mencari tambahan penghasilan dan lain-lain.

Pembelajaran online bisa menjadi solusi dalam masalah ini karena tidak terbatas ruang dan waktu. Siswa bisa mengakses Edmodo sewaktu-waktu. Dengan pelatihan ini guru bisa lebih kreatif dalam merancang pembelajaran.

Minat belajar siswa akan meningkat apabila pembelajaran yang disampaikan guru juga menarik. Dari tanggapan guru yang menerapkan pembelajaran ini, siswa sangat tertarik menyelesaikan tugas-tugas yang diberikan. Hal ini menandakan bahwa pelatihan ini memberikan hasil yangpositif bagi guru dan siswa.

\section{KESIMPULAN DAN SARAN}

Kesimpulan dari pengabdian ini adalah pembelajaran Edmodo dapat membuat guru lebih kreatif. Sejalan dengan hal tersebut, minat belajar siswa semakin bertambah. Pelatihan-pelatihan yang mengacu kepada pembelajaran akan terasa menyenangkan dan lebih menarik.

Saran bagi pemerintah, pemerintah lebih tanggap dalam masalah perkembangan pendidikan di Indonesia salah satunya dengan pelatihan-pelatihan seperti ini. Saran kepada pengabdian kepada masyarakat lanjutan yaitu perlu diadakan pelatihan pembelajaran berbasis online selain Edmodo.

\section{UCAPAN TERIMA KASIH}

Ucapan terimakasih disampaikan kepada LPPM STKIP Modern Ngawi, Kepala Madrasah MTs Darul Hikmah Ngompak Ngrambe, Wakil Kepala Kurikulum MTs Darul Hikmah Ngompak, Siswa/siswi MTs Darul Hikmah Ngompak Ngrambe, dan pihakpihak lain yang telah membantu dalam pelaksanaan pengabdian ini.

\section{DAFTAR PUSTAKA}

Fitriasari, Putri. 2016. "Aplikasi Edmodo Sebagai Media Pembelajaran ELearning".jurnal Universitas PGRI palembang. Vol 26

Kustandi, C. dan Bambang S. (2011). Media Pembelajaran; Manual dan Digital. Bogor: Penerbit Ghalia Indonesia.

Yunus, F. 2013. Edmodo untuk Aplikasi Pembelajaran Kolaboratif. Melalui http://www.edmodo.com/file/viewcrocodoc-new-window?uuid=de94 9a0b-0b9a-43c79fca85447ce6036f. 


\section{LAMPIRAN}

\section{Tabel 1. Rubrik Penilaian Simulasi}

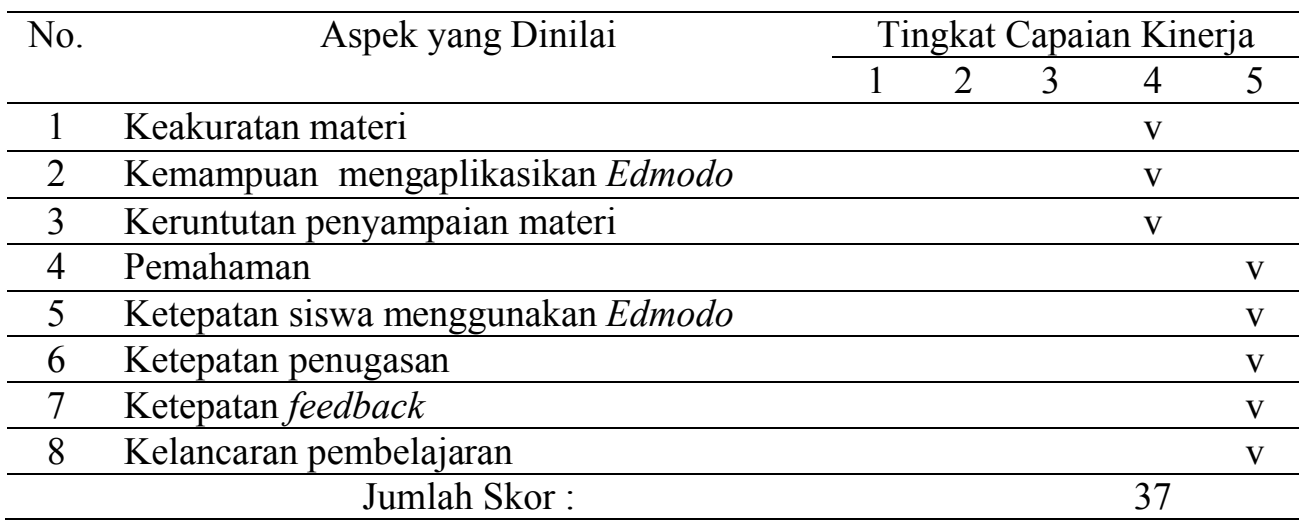

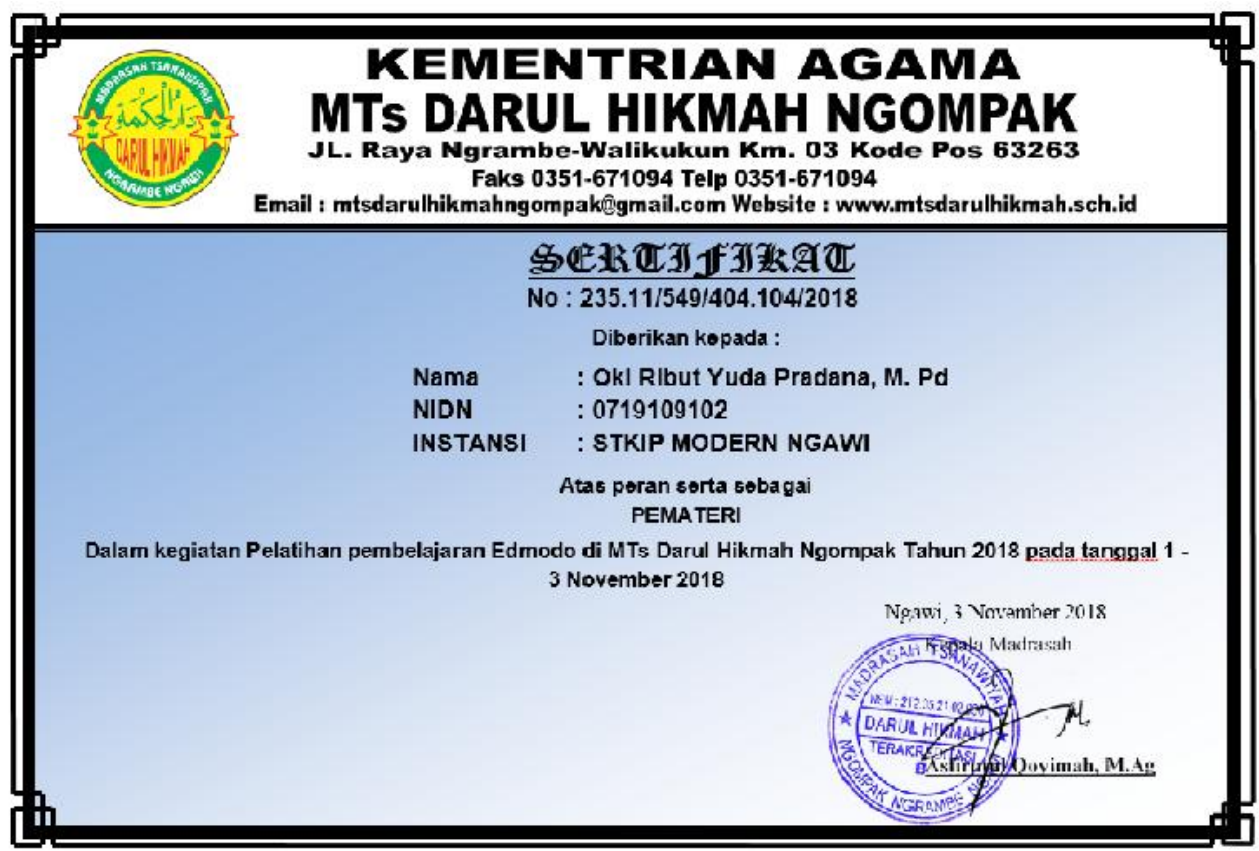



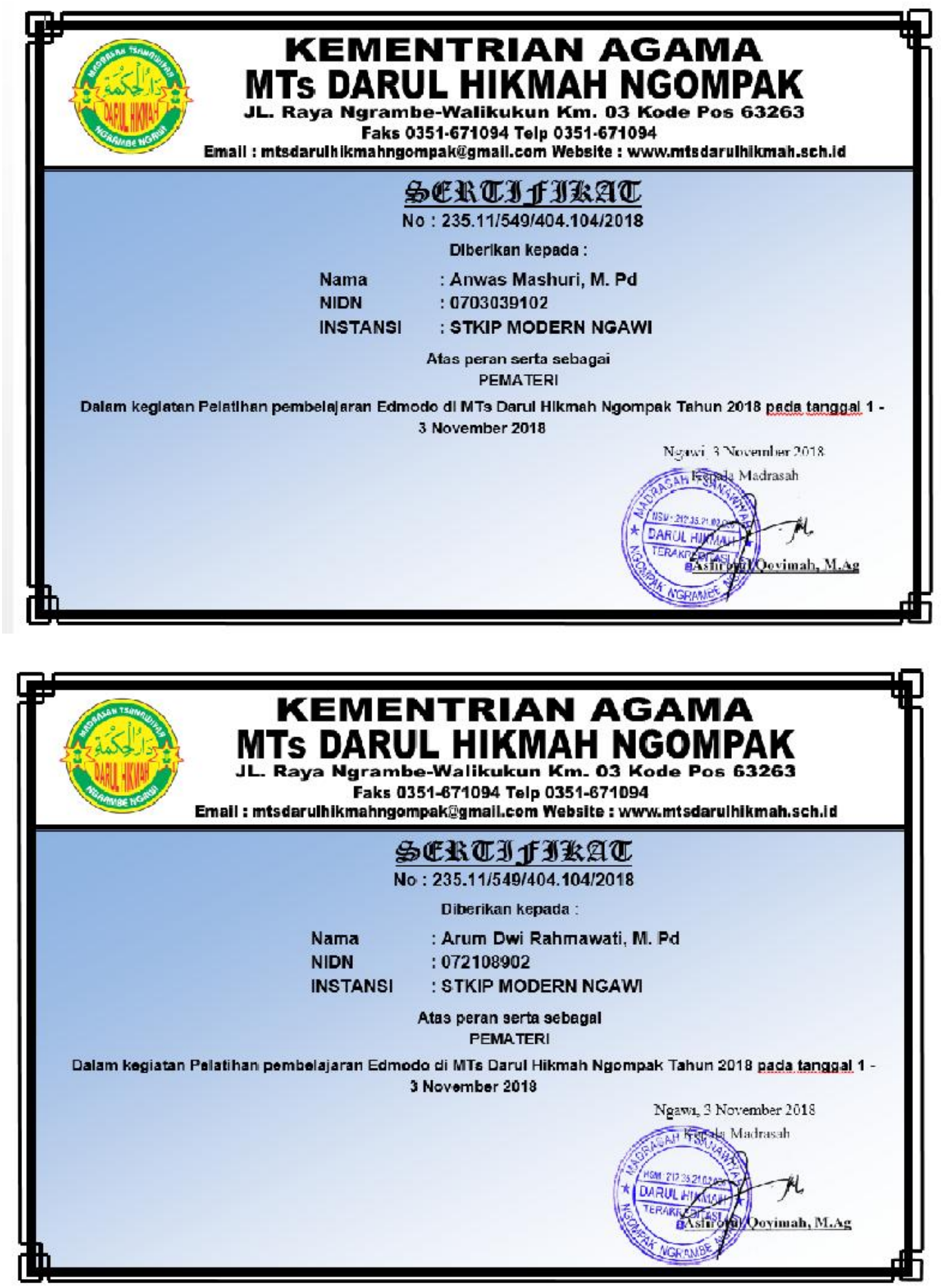


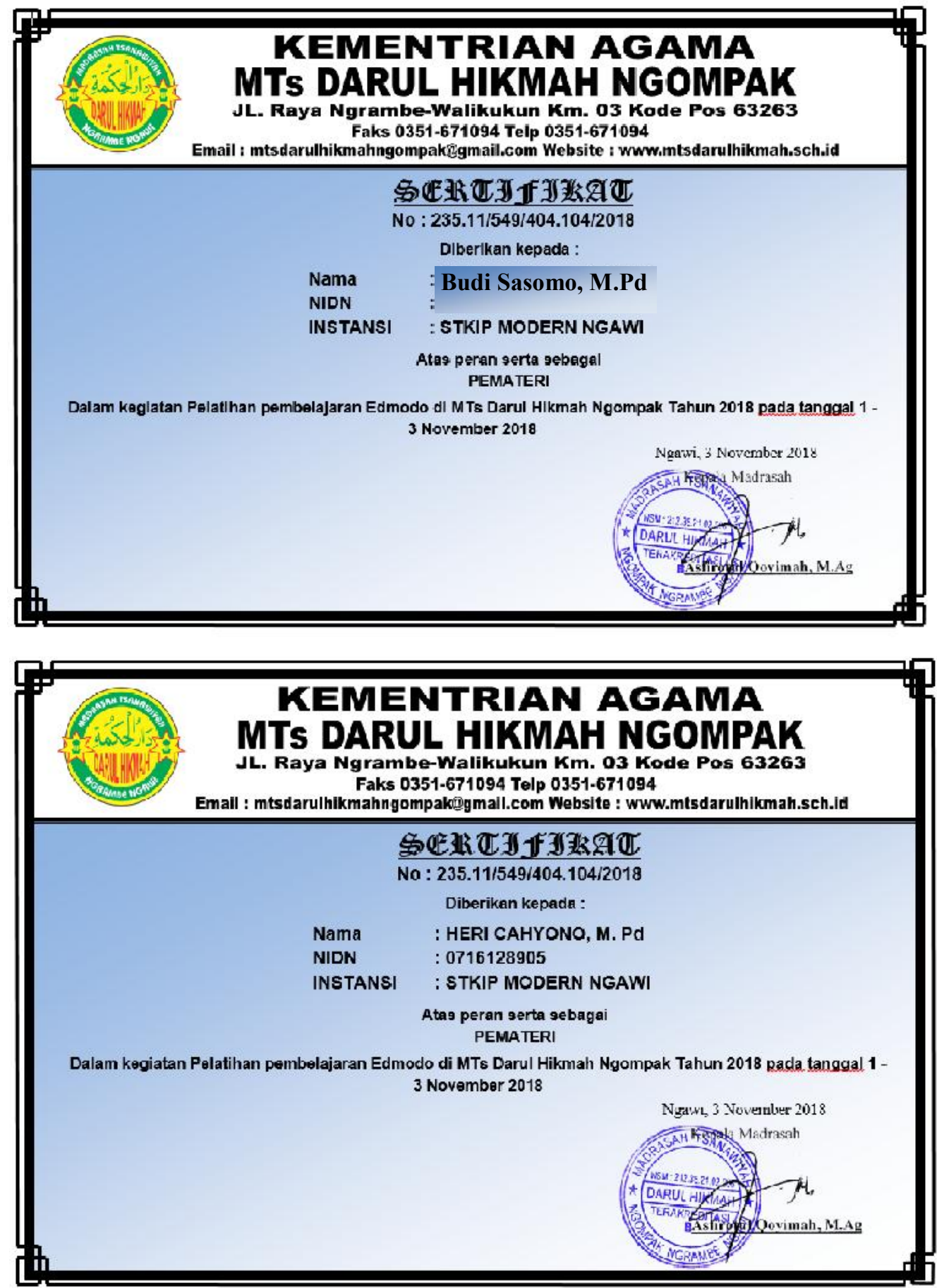

Sumber: Asfirotul (2018: 3)

Gambar 1. Sertifikat Pelatihan Pemateri 